\title{
Assessment of fitness in patients with cystic fibrosis and mild lung disease
}

\author{
P McLoughlin, D McKeogh, P Byrne, G Finlay, J Hayes, M X FitzGerald
}

\begin{abstract}
Background - Maximal exercise testing is used in patients with cystic fibrosis to assess functional status and prognosis. The lactate threshold is an index of aerobic fitness with significant advantages over maximal exercise tests. This study was undertaken to determine if the lactate threshold might be identified, non-invasively, in adult patients with cystic fibrosis and mild lung disease by measurement of ventilatory and gas exchange parameters.

Methods - Ten subjects with mild cystic fibrosis (forced vital capacity (FVC) $>70 \%$ predicted) and 10 healthy controls undertook an incremental exercise test on a bicycle ergometer. Ventilation and gas exchange parameters were measured continually and arterialised venous blood $\mathrm{pH}$, carbon dioxide tension $\left(\mathrm{PCO}_{2}\right)$, and lactate concentrations were measured at intervals throughout the tests.

Results - In subjects with cystic fibrosis there was no significant difference between the mean gas exchange and lactate thresholds (mean difference 1.0 (95\% confidence interval (CI) of the mean -1.5 to 3.44 ) $\mathrm{ml} /$ $\mathrm{kg} / \mathrm{min})$. In contrast, there was a significant difference between the mean ventilatory and lactate thresholds (3.8 (95\% CI 0.9 to 6.7$) \mathrm{ml} / \mathrm{kg} / \mathrm{min})$. Arterialised venous $\mathrm{PCO}_{2}$ increased significantly during the exercise tests. In healthy subjects the mean differences between these thresholds were not significantly different from zero and $\mathrm{PCO}_{2}$ fell significantly during the tests. Conclusions - The ventilatory threshold significantly overestimates the lactate threshold in subjects with cystic fibrosis induced lung disease because of impaired carbon dioxide excretion during exercise. However, the gas exchange threshold may be used to determine the lactate threshold in this patient group.

(Thorax 1997;52:425-430)
\end{abstract}

Keywords: cystic fibrosis, exercise, lactate threshold, gas exchange threshold.

Regular aerobic exercise can form an important part of the treatment programme of patients with cystic fibrosis. ${ }^{1}$ Such exercise promotes sputum clearance, ${ }^{2-4}$ improves functional status, ${ }^{5-7}$ and fosters a feeling of well-being. ${ }^{7}$ More recently it has been reported that prolonged survival in these patients is associated with higher levels of performance in formal exercise tests, leading to the suggestion that regular aerobic training may increase life expectancy. ${ }^{8}$ To investigate this important issue, improved methods of quantifying aerobic fitness are required which are not excessively stressful and are readily acceptable to patients.

Various techniques have been used to assess fitness in subjects with cystic fibrosis including maximal oxygen consumption, maximum power output, time to exhaustion during incremental exercise tests, time to exhaustion at a fixed work load, or time taken to complete a fixed distance. ${ }^{589}$ However, there are many difficulties associated with their use in this context. ${ }^{10}$ In particular, all require the subject to make maximal efforts, rendering such tests highly dependent on motivation.

The lactate threshold is an alternative index of aerobic fitness which has been widely used in athletes. As the workload progressively increases during an incremental exercise test, a critical exercise intensity is reached above which blood lactate levels increase progressively, reflecting an abrupt rise in lactate concentration in the exercising muscles. ${ }^{10}$ The oxygen uptake of the subject at this critical work load is called the lactate threshold (LT), which is a better indicator of aerobic fitness than other indices commonly used. It permits identification of the optimum training intensity for an individual and does not require exercise to exhaustion for its determination. ${ }^{10-14}$

In healthy subjects the LT may be determined non-invasively by identification of the ventilatory threshold (VenT) which is defined as the point during an incremental exercise test when ventilation breaks away from its initial linear relationship to oxygen uptake $\left(\mathrm{V}_{2}\right) .{ }^{10}$ Subjects with significant obstructive lung disease frequently are unable to produce this hyperventilatory response. However, in these patients it is possible to detect a non-linear increase in carbon dioxide output in relation to $\mathrm{VO}_{2}$ - the gas exchange threshold (GET) which coincides with the LT. ${ }^{1516}$

The lung disease associated with cystic fibrosis leads to a characteristic pattern of pathophysiological disturbances even at an early stage when spirometric abnormalities are minimal or mild. In particular, there are disproportionately large increases in physiological dead space and shunt. ${ }^{1718}$ By impairing carbon dioxide excretion these disturbances might prevent the identification of the ventilatory and gas exchange thresholds.

The primary purpose of the present study was to determine if the LT might be identified non-invasively in adult cystic fibrosis patients with mild to moderate lung disease by measure- 
ment of ventilatory and gas exchange parameters and thus provide an easily determined index of aerobic fitness.

\section{Methods}

Ten male subjects ( $>14$ years of age) with cystic fibrosis (sweat test demonstrated sodium and chloride concentrations $>60 \mathrm{mmol} / \mathrm{l}$ ) and mild to moderate lung disease (forced vital capacity (FVC) $>70 \%$ of predicted) were recruited from the Adult Cystic Fibrosis Clinic at St Vincent's Hospital. Ten non-smoking control subjects who had no history of significant cardiopulmonary disease were also recruited. The study was approved by the hospital ethics committee and all participants gave written informed consent.

Each subject attended the exercise laboratory on a single occasion and completed an incremental exercise test to exhaustion on a friction braked cycle ergometer (Monark, Sweden). Subjects were instructed to maintain a constant pedalling rate. To facilitate this, their actual pedalling rate was displayed continuously to the subject. The test began with a four minute period of unloaded cycling after which the workload was increased every two minutes by $10-20 \mathrm{~W}$, depending on the stature and exercise history of the subject. They did not come to the laboratory for prior training or acclimatisation.

Subjects wore a nose clip and mouthpiece connected to a non-rebreathing valve. Minute ventilation $(\dot{\mathrm{VE}})$, oxygen uptake $\left(\mathrm{V}_{2}\right)$, and carbon dioxide output $\left(\mathrm{V} \mathrm{CO}_{2}\right)$ were determined at 15 second intervals using a computerised system (PK Morgan, Kent, UK). Inspiratory flow rates were measured with a turbine flow meter and electrically integrated to give volume. Expired gas passed through a mixing chamber and was then continuously sampled for determination of mixed expired gas composition. Oxygen saturation (Biox 3700E, Ohmeda, Colorado, USA) and an ECG were monitored throughout the exercise tests. Calibrations were checked before and after each test using calibration syringes and precision oxygen and carbon dioxide gas mixes (BOC, Ireland).

Forced expiratory volume in one second $\left(\mathrm{FEV}_{1}\right)$ and FVC were measured with a model S spirometer (Vitalograph Ltd, Bucks, UK) before exercise and peak flow was determined both before and after the exercise test. Predicted values of these variables were calculated using the equations of Quanjer et al. ${ }^{19}$ Predicted maximum voluntary ventilation (MVV) was calculated as $\mathrm{FEV}_{1} \times 37.5 .^{20}$ Predicted maximum heart rate was calculated as $220-$ age in years. ${ }^{21}$

Arterialised venous blood samples were drawn over the last 15 seconds of each workload as previously described. ${ }^{22}$ A portion of each sample was stored anaerobically on ice for subsequent measurement of $\mathrm{pH}$ and $\mathrm{PCO}_{2}$ using an automated self-calibrating blood gas analyser (Model IL 1312 Blood Gas Manager; Allied Instruments Lab, Cheshire, UK). $1.0 \mathrm{ml}$ of the remaining blood was pipetted into $2.0 \mathrm{ml}$ of

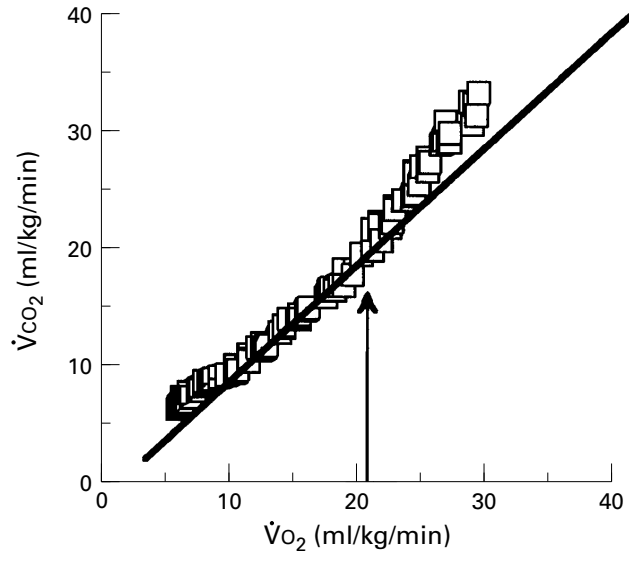

Figure 1 Determination of the gas exchange threshold in a single subject with cystic fibrosis. A line parallel to the line of identity was selected by a blinded reviewer to indicate the point at which $\mathrm{VCO}_{2}$ began to increase more rapidly than $\mathrm{VO}_{2}$ (arrow). See text for details.

chilled $7 \%$ perchloric acid and the supernatant assayed for lactate concentration using an enzymatic, spectrophotometric technique (Sigma Diagnostics Procedure No. 826-uv; Sigma Laboratories, Dorset, UK).

\section{CALCULATIONS}

All determinations of lactate, ventilatory, and gas exchange thresholds were performed by a blinded observer. The GET was identified using the modified V-slope method of Sue et $a l^{15}$ and the Ven $T$ was determined by identifying the point at which the ventilatory equivalents for oxygen began a steady progressive rise after a period when they had been unchanging or progressively falling. ${ }^{10}$ The LT was determined using the method of Beaver et al. ${ }^{23}$ All thresholds were expressed as oxygen uptake $(\mathrm{ml} / \mathrm{kg} /$ $\min )$.

Figure 1 illustrates the method of determining the GET in a single subject. $\mathrm{VCO}_{2}$ is plotted against $\dot{\mathrm{VO}}_{2}$ and a line parallel to the line of identity is plotted through the lower data points. This is most conveniently accomplished by drawing the $x$ and $y$ axes of the $\mathrm{VCO}_{2}$ versus $\dot{\mathrm{V}}_{2}$ plot to an exactly equal scale, ensuring that the line of identity makes an angle of $45^{\circ}$ (slope of 1 ) with the $x$ axis. A $45^{\circ}$ set square is then placed on the $x$ axis so that so that its angled edge lies parallel to the line of identity. By moving the set square horizontally along the $x$ axis a best-fit line may be drawn through the lower data points by eye. This manoeuvre identifies the point during the exercise test, expressed as $\dot{\mathrm{VO}}_{2}(\mathrm{ml} / \mathrm{kg} / \mathrm{min})$, when $\dot{\mathrm{VCO}}_{2}$ begins to rise disproportionately faster than $\mathrm{VO}_{2}$ due to a sudden increase in lactic acid concentration within the exercising muscles. The slope of a line through the data points below the lactate threshold is approximately equal to 1 because exercising muscle primarily uses glycogen as a source of energy. As a consequence, the ratio of the increase in $\mathrm{VCO}_{2}$ to the increase in $\dot{\mathrm{VO}}_{2}$ is approximately $1 .{ }^{15}$ 


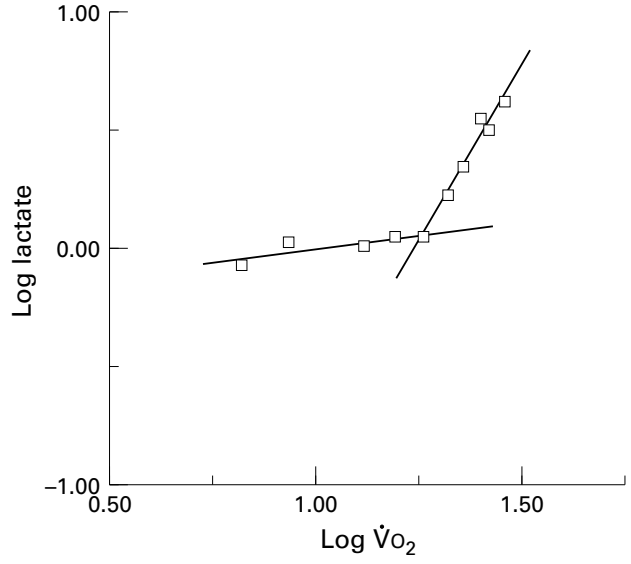

Figure 2 Determination of the lactate threshold (LT) for the same subject as in fig 1 . The logarithm of blood lactate concentration was plotted against the logarithm of the mean $\mathrm{VO}_{2}$ during the minute in which that blood sample was drawn. The lactate threshold was determined as the point of intersection of the two least squares regression lines fitted to the data points before and after the onset of a rapid increase in lactate concentration (chosen by blinded reviewer). See text for details.

Figure 2 demonstrates the method of identification of the LT using data obtained from the same subject as in fig 1 . Log lactate concentration is plotted against $\log \dot{\mathrm{VO}}_{2}$ and the point of inflection was chosen by a blinded reviewer. Using least squares regression a straight line was fitted to the data points below and including the chosen inflection point and a separate line to the data points above and including the inflection point. The intersection of these two lines indicates the LT which is expressed as $\dot{\mathrm{VO}}_{2}(\mathrm{ml} / \mathrm{kg} / \mathrm{min}) .^{23}$

Table 1 Mean (SD) anthropometric characteristics, pulmonary function and measured blood parameters at rest in patient and control groups $(n=10)$

\begin{tabular}{llc}
\hline & Patients & Controls \\
\hline Age (years) & $25.4(4.3)$ & $24.1(1.4)$ \\
Height (m) & $1.75(0.05)^{*}$ & $1.80(0.05)$ \\
Weight (kg) & $65.8(9.0)^{* *}$ & $80.4(10.8)$ \\
FEV $_{1}$ (\% predicted) & $80.4(15.6)^{* *}$ & $103.9(11.0)$ \\
$\mathrm{FVC}_{\text {(\% predicted) }}$ & $96.9(15.8)$ & $107.7(14.9)$ \\
$\mathrm{FEV}_{1} / \mathrm{FVC}$ & $70.4(9.7)^{* *}$ & $81.8(7.9)$ \\
pH & $7.415(0.018)$ & $7.406(0.014)$ \\
PcO $_{2}(\mathrm{kPa})$ & $4.9(0.3)$ & $5.2(0.3)$ \\
Actual bicarbonate (mmol/l) & $23.1(1.2)$ & $23.9(1.2)$ \\
Blood lactate (mmol/l) & $1.2(0.3)$ & $0.8(0.2)$ \\
\hline
\end{tabular}

$\mathrm{FEV}_{1}=$ forced expiratory volume in one second; $\mathrm{FVC}=$ forced vital capacity; $\mathrm{PCO}_{2}=$ carbon dioxide tension.

${ }^{*} \mathrm{p}<0.05, * * \mathrm{p}<0.01$ (unpaired $t$ test) compared with control value.

Table 2 Mean (SD) blood and ventilatory parameters, heart rate and measured blood parameters at peak exercise in patient and control groups $(n=10)$

\begin{tabular}{llc}
\hline & Patients & Controls \\
\hline Peak $\mathrm{Vo}_{2}(\mathrm{ml} / \mathrm{kg} / \mathrm{min})$ & $32.4(5.7)^{* *}$ & $42.5(6.1)$ \\
Ventilation (\% MVV) & $63.5(15.3)$ & $64.7(9.6)$ \\
Heart rate (\% predicted maximum) & $94.4(5.1)$ & $95.6(8.3)$ \\
$\mathrm{pH}$ & $7.290(0.023)$ & $7.272(0.042)$ \\
$\mathrm{PCO}_{2}(\mathrm{kPa})$ & $5.3(0.5)$ & $4.8(0.5)$ \\
Actual bicarbonate $(\mathrm{mmol} / \mathrm{l})$ & $18.6(1.7)^{* *}$ & $16.1(1.7)$ \\
Blood lactate (mmol/1) & $5.4(1.6)^{* *}$ & $8.3(2.4)$ \\
\hline
\end{tabular}

$\mathrm{VO}_{2}=$ oxygen uptakes; $\mathrm{MVV}=$ maximum voluntary ventilation; $\mathrm{PCO}_{2}=$ carbon dioxide tension

$* * \mathrm{p}<0.01$ (unpaired $t$ test) compared with control value.
DATA ANALYSIS

One group $t$ tests, unpaired $t$ tests or analysis of variance (ANOVA) with repeated measures were used as appropriate. When the overall ANOVA was statistically significant, Student Neuman Keul's post hoc test (SNK) was used to assess the significances of the differences between specific means. The method of Bland and Altman was employed to compare the values determined for the anaerobic threshold using the lactate, gas exchange, and ventilatory threshold methods. ${ }^{24}$

\section{Results}

Anthropometric, pre-exercise pulmonary function, and resting arterialised venous blood data for both patient and control groups are given in table 1 . The patients were of lower mean height $(\mathrm{p}<0.05$, unpaired $t$ test $)$ and weight $(\mathrm{p}<0.01$, unpaired $t$ test) than the control subjects and had evidence of obstructive airways disease. The mean (range) Shwachman score for the patient group was 75 (66-85). Table 2 shows values recorded at peak work load. Both patients and controls had developed a marked metabolic acidosis at the end of the exercise test and the blood lactate levels were increased in all participants by more than $3 \mathrm{mmol} / \mathrm{l}$. The mean maximum ventilation at peak exercise in both the cystic fibrosis and control groups was markedly less than the MVV (table 2), while heart rate was near maximal. The peak flow after exercise was not reduced below the preexercise values in any of the study participants.

In subjects with cystic fibrosis the mean difference $(95 \%$ confidence interval of the mean) between the GET and the LT was 1.0 $(-1.5$ to 3.44$) \mathrm{ml} / \mathrm{kg} / \mathrm{min}$, not significantly different from zero ( $\mathrm{p}>0.05$, one sample $t$ test). This indicates that the GET could be used to provide an unbiased estimate of the LT in a group of patients with cystic fibrosis. The mean difference between the LT and the VenT was $3.8(0.9$ to 6.7$) \mathrm{ml} / \mathrm{kg} / \mathrm{min}$, a value significantly greater than zero $(\mathrm{p}<0.05$, one sample $t$ test). This suggests that use of the VenT would lead to an overestimate of the LT in a population of cystic fibrosis patients. The corresponding comparisons for the control groups demonstrated a mean difference between LT and GET of -0.1 ( -2.5 to 2.3$) \mathrm{ml} / \mathrm{kg} / \mathrm{min}$ and a mean difference between LT and VenT of 1.9 $(-1.8$ to 5.5$) \mathrm{ml} / \mathrm{kg} / \mathrm{min}$, neither of which are significantly different from zero $(p>0.05$, one sample $t$ test).

In order to illustrate the agreement of the GET and LT within individual subjects, a comparison of the two thresholds in the patient group is shown in fig 3 using the technique of Bland and Altman. ${ }^{24}$ For each subject the difference between the LT and GET is plotted against the average of the two determinations. The limits of agreement (mean $\pm 2.262 \times \mathrm{SD}$ of differences) are also shown $(-6.8$ to $8.8 \mathrm{ml} /$ $\mathrm{kg} / \mathrm{min}$ ). For the control group the limits of agreement were similar ( -7.6 to 7.6$)$.

We examined the behaviour of arterialised venous $\mathrm{PCO}_{2}$ throughout the incremental tests (fig 4). For each subject the value of arterialised 


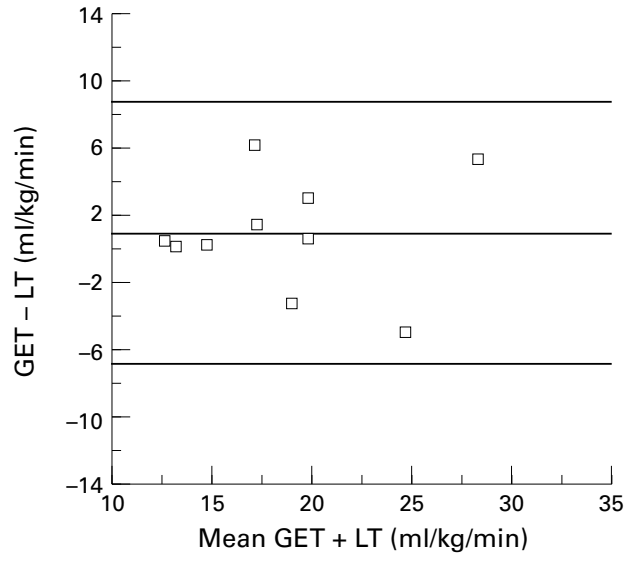

Figure 3 Comparison of gas exchange threshold (GET) and lactate threshold (LT) in patients with cystic fibrosis. For each subject the difference between the $\dot{V}_{2}$ at the gas exchange and lactate thresholds is plotted against the average of the two values. The mean of the differences, indicated by the middle horizontal line, is not significantly different from zero ( $p>0.05$, unpaired $t$ test). Upper and lower lines indicate the limits of agreement (mean \pm $2.262 \times S D$ of the differences).
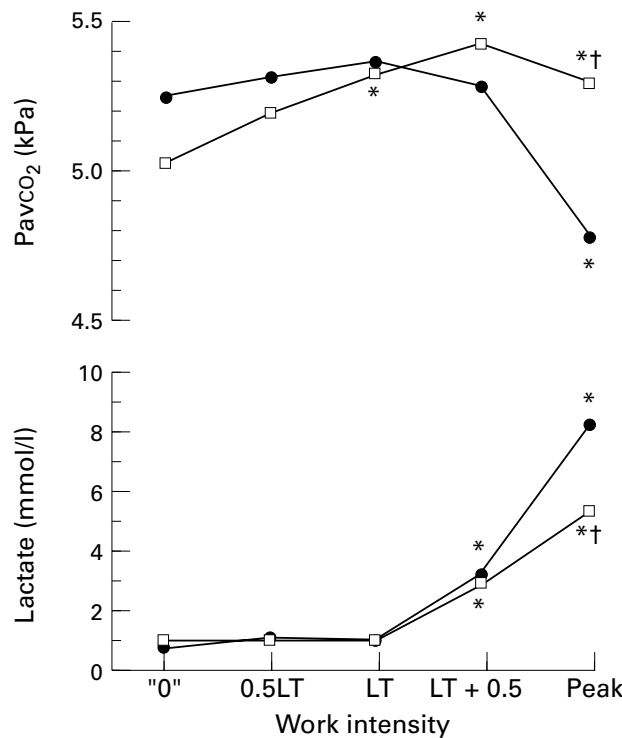

Figure 4 Mean arterialised venous $\mathrm{PCO}_{2}$ and blood lactate concentration plotted against work load during incremental exercise tests for both control (O) and cystic fibrosis ( $\square$ ) groups. " 0 " =unloaded cycling; 0.5LT= work load which elicits a $\dot{V}_{2}$ of $50 \%$ that at the $L T$ $L T=$ work load at $L T ; L T+0.5 \Delta=$ work load which elicited a $\dot{V O}_{2}$ equal to that at the LT plus half of the difference between $\dot{V}_{2}$ at $L T$ and peak $\dot{V}_{2}$; peak $\dot{V O}_{2}=$ $\dot{V}_{2}$ at peak work load. ${ }^{*} p<0.05$ (SNK) compared with value at " 0 " work load; $t p<0.05$ (SNK) compared with value at same work load in control group.

venous $\mathrm{PCO}_{2}$ and lactate was determined during (a) unloaded cycling ("O" WL), (b) at a work load which elicited a $\mathrm{VO}_{2}$ half way between " 0 " work load and the LT (0.5 LT), (c) at the LT, (d) at a work load which elicited a $\mathrm{VO}_{2}$ that lay half way between the LT and the maximum work load $(\mathrm{LT}+0.5 \Delta)$, and (e) at the peak work load completed (Peak WL). The mean value of these variables for patient and control groups was then plotted against the corresponding work load (fig 4). Both groups demonstrated a significant increase in blood lactate levels at heavier work loads, although the increase was greater in the controls $(\mathrm{p}<0.01$, $\mathrm{SNK}$ ). However, the behaviour of arterialised venous $\mathrm{PCO}_{2}$ in the patients was significantly different from that of controls $(\mathrm{p}<0.01$, ANOVA). In the control group mean blood $\mathrm{PCO}_{2}$ remained relatively constant up to the LT following which it fell progressively. Thus, at peak work load it lay below the value at " 0 " work load ( $p<0.01, \mathrm{SNK})$. In contrast, in the patient group blood $\mathrm{PCO}_{2}$ rose progressively $(p<0.01, S N K)$ until a work load well above the LT and then fell slightly although remaining significantly raised $(p<0.05, \mathrm{SNK})$ above the value at " 0 " work load. At maximal work load blood $\mathrm{PCO}_{2}$ was reduced below the initial value in only one of the patient tests.

\section{Discussion}

The findings of the present study indicate that in patients with cystic fibrosis and mild pulmonary impairment the non-invasive technique of the gas exchange threshold can provide an accurate estimate of the lactate threshold. In contrast, determination of the ventilatory threshold by the ventilatory equivalents method leads to a significant overestimate of the lactate threshold. In contrast, in our healthy control subjects both ventilatory threshold and gas exchange threshold methods agreed well with the lactate threshold, as previously reported by others. ${ }^{10}$

The subjects with cystic fibrosis did not hyperventilate normally following the onset of lactic acidosis, as shown by the absence of a fall in arterialised venous $\mathrm{PCO}_{2}$ at heavier work loads (fig 4). This finding is in contrast to previous reports that patients with mild to moderate cystic fibrosis induced lung disease do not retain carbon dioxide during exercise. ${ }^{2526}$ The differing findings may have arisen because previous workers used end tidal carbon dioxide as an index of arterial carbon dioxide whereas in the present study we have measured blood $\mathrm{PCO}_{2}$ directly. ${ }^{2526}$

The impaired carbon dioxide excretion which we observed was not due to ventilatory limitation since the mean (SD) maximum minute ventilation of these patients was only 63.5 (15.3)\% of the predicted maximum voluntary ventilation, whereas the mean maximum heart rates were greater than $90 \%$ predicted maximum in both groups (table 2). A mechanism which may have contributed to the impaired excretion of carbon dioxide during exercise is an increase in physiological dead space ventilation which has been reported in patients with cystic fibrosis, even when standard spirometric tests are only mildly abnormal. ${ }^{18}$ This abnormal increase in physiological dead space ventilation may arise because of abnormalities of ventilation-perfusion matching in the lung. In patients with cystic fibrosis abnormalities in the pattern of response of tidal volume and frequency of breathing to ventilatory stimuli may also contribute. ${ }^{27} \mathrm{~A}$ second factor which may contribute to hypercapnia is the presence of obstructive airways disease (table 1). Sub- 
jects with well controlled asthma and healthy subjects breathing through an added resistance fail to show normal hyperventilation at heavier work loads. ${ }^{28}$ The impaired carbon dioxide excretion at higher work loads is not due to a blunted central ventilatory response to hypercapnia since this is normal in patients with mild to moderate cystic fibrosis induced lung disease. ${ }^{27}$

All of the subjects with cystic fibrosis were able to continue to a work load which caused a significant metabolic acidosis (blood lactate $>3 \mathrm{mmol} / \mathrm{l}$ ). In addition, none of them demonstrated a lactate threshold until more than two minutes of the incremental exercise test had elapsed, so the gas exchange threshold occurred at a time when carbon dioxide and oxygen stores were changing at a constant rate. These are the necessary conditions which must be met to allow identification of the gas exchange threshold. ${ }^{1516}$ In patients with more severe lung disease these criteria may not be satisfied. Thus, to determine if the findings of the present study can be extended to those in whom FVC is less than $70 \%$ predicted, further work is required.

We have found that, in patients with cystic fibrosis and mild lung disease, the gas exchange threshold provides an unbiased estimate of the lactate threshold. The standard deviation of the differences in the patient group $(3.5 \mathrm{ml} /$ $\mathrm{kg} / \mathrm{min}$ ) was identical to that of the controls $(3.5 \mathrm{ml} / \mathrm{kg} / \mathrm{min})$, indicating that the technique is equally precise in both patients with mild cystic fibrosis and healthy subjects. Furthermore, the standard deviation is similar to those of previously published studies of patients with smoking related lung disease. ${ }^{1529}$ To compare our data with previous reports we converted the oxygen consumptions at the gas exchange thresholds to $1 / \mathrm{min}$. The resultant standard deviation of the differences $(0.230 \mathrm{l} /$ min) was identical to that reported by Dickstein and colleagues in subjects with chronic obstructive pulmonary disease. ${ }^{29}$ In another study of subjects with chronic obstructive pulmonary disease Sue et al compared gas exchange and bicarbonate thresholds and observed a value of $0.215 \mathrm{l} / \mathrm{min}$ for the standard deviation of the differences, a value similar to that of the present study. ${ }^{15}$

The reproducibility of the determination of the gas exchange and lactate thresholds is clearly relevant to the method comparison which we report here. The reproducibilities of the two methods limit the agreement which is possible between them. ${ }^{24}$ To determine the reproducibility of each method would require two tests on each subject separated by a short interval (7-10 days) during which the subjects remained stable. We are unaware of any studies in patients with cystic fibrosis or in normal subjects which examine this issue based on the methods which we have used. Two groups have examined this issue in normal subjects using somewhat different methodologies. Smith and O'Donnell reported a study of reproducibility using a cumulative sum method to determine the ventilatory threshold and found that the mean difference between replicate tests was
$0.001 \mathrm{l} / \mathrm{min}$ with a standard deviation of $0.2201 / \mathrm{min} .{ }^{30}$ Caiozzo et al showed good linear correlation between the values of $\mathrm{Vo}_{2}$ at the gas exchange threshold obtained in individual subjects on two separate occasions and found that the standard error of the estimate was $0.260 \mathrm{l} / \mathrm{min} .{ }^{31}$ Neither group examined the reproducibility of determinations of the lactate threshold. It is interesting to note that the standard deviation of the difference reported by Smith and O'Donnell and the standard error of the estimate reported by Caiozzo et al are similar to the standard deviation of the differences between the gas exchange and lactate thresholds in the present study.

Exercise tests were continued to exhaustion in our study. This protocol was adopted to allow exploration of the ventilatory responses throughout an incremental exercise test. If the sole object of an exercise test is to determine the gas exchange threshold in order to assess aerobic fitness, then to continue exercise to the maximal tolerated effort is not necessary. The test may be stopped when sufficient data have been collected to allow identification of the "breakpoint" in the plot of $\mathrm{VCO}_{2}$ against $\mathrm{VO}_{2}$. It is our experience that this can usually be achieved when the subject has reached a work load which lies approximately half way between the lactate threshold and the maximum work load. This intensity of exercise does not cause severe "distress" and may be achieved without requiring exceptional self-motivation.

Use of the gas exchange threshold as a means of assessing fitness in patients with cystic fibrosis offers several further advantages over the commonly employed maximal tests. It is an excellent index of aerobic performance, it can increase following training even in the absence of changes in $\mathrm{VO}_{2} \mathrm{max}$, and the changes observed are closely correlated with improved endurance performance. ${ }^{10-1214}$ This may be especially important when maximal performance is limited by ventilatory capacity. In this circumstance, training can lead to important cardiac and skeletal muscle effects which lead to improved performance at submaximal work loads. ${ }^{14}$ The gas exchange threshold provides an index of performance at such submaximal work loads, information which is directly relevant to a patient's ability to carry out the tasks of daily living. ${ }^{10}$ Finally, the gas exchange threshold allows determination of the optimum training intensity in an individual. ${ }^{1314}$

In conclusion, the ventilatory threshold significantly overestimates the lactate threshold in subjects with mild cystic fibrosis induced lung disease because of impaired carbon dioxide excretion during exercise. However, the gas exchange threshold may be used to estimate the lactate threshold in this patient group, both accurately and non-invasively. It provides an index of aerobic fitness which offers significant advantages over previously used methods which depend upon maximal exercise effort.

We gratefully acknowledge the support of the Cystic Fibrosi Association (Ireland) and the Health Research Board (Ireland) We also wish to thank the staff of the Biochemistry Laboratories at St Vincent's Hospital. 
1 Webb AK, David TJ. Clinical management of children and adults with cystic fibrosis. BMF 1994;308:459-61.

2 Lannefors L, Wollmer P. Mucus clearance with three chest physiotherapy regimes in cystic fibrosis: a comparison between postural drainage, PEP and physical exercise. Eur Respir f 1992;5:748-53.

3 Zach MS, Purrer B, Oberwaldner B. Effect of swimming on forced expiration and sputum clearance in cystic fibrosis. Lancet 1981;ii:1201-3.

4 Salh W, Dilton D, Dodd M, Webb AK. Effect of exercise and physiotherapy in aiding sputum expectoration in adults with cystic fibrosis. Thorax 1989;44:1006-8.

5 Braggion C, Cornacchia M, Miano A, Schena F, Verlato G, Mastella G. Exercise tolerance and effects of training Mastella G. Exercise tolerance and effects of training in young patients with cystic fibrosis and
obstruction. Pediatr Pulmonol $1989 ; 7: 145-52$

6 Edlund LD, French RW, Herbst JJ, Ruttenberg HD, Ruhling RO, Adams TD. Effects of a swimming program on children with cystic fibrosis. Sports Med 1986;140:80-3.

7 Stanghelle JK. Physical exercise for patients with cystic fibrosis: a review. Int 7 Sports Med 1988;9(Suppl):6-18.

8 Nixon PP, Orenstein DM, Kelsey SF, Doershuk CF. The prognostic value of exercise testing in patients with cystic fibrosis. N Engl f Med 1992;327:1785-8.

9 Heijerman HGM, Bakker W, Sterk PJ, Dijkman JJH. Oxygen-assisted exercise training in adult cystic fibrosis patients with pulmo

10 Wasserman $\mathrm{K}$. The anaerobic threshold measurement to evaluate exercise performance. Am Rev Respir Dis 1984; 129(Suppl):S35-40.

11 Farrell PA, Wilmore JH, Coyle EF, Billings JE, Costill DL. Plasma lactate accumulation and distance running

12 Kumagi S, Tanaka K, Matsura Y, Matsuzaka A, Hirakoba $\mathrm{K}$, Asano K. Relationships of the anaerobic threshold with the $5 \mathrm{~km}, 10 \mathrm{~km}$ and 10 mile races. Eur $\mathcal{f}$ Appl Physiol 1982;49:13-23.

13 Kinderman W, Simon G, Keul J. The significance of the anaerobic threshold transition for the determination of work intensities during endurance training. Eur 7 Appl Physiol 1979;42:25-34.

14 Casaburi R, Patessio A, Ioli F, Zanaboni S, Donner CF, Wasserman K. Reductions in exercise lactic acidosis and ventilation as a result of exercise training in patients with obstructive lung disease. Am Rev Respir Dis 1991;143: obstru.

15 Sue DY, Wasserman K, Moricca RB, Casaburi R. Metabolic acidosis during exercise in patients with chronic obstructive pulmonary disease. Chest 1988;94:931-8.

16 Patessio A, Casaburi R, Carone M, Appendini L, Donner $\mathrm{CF}$, Wasserman $\mathrm{K}$. Comparison of gas exchange, lactate, and lactic acidosis thresholds in patients with chronic obstructive pulmonary disease. Am Rev Respir Dis 1993 148:622-6.

7 Dantzker DR, Patten GA, Bower JS. Gas exchange at rest and during exercise in adults with cystic fibrosis. Am Rev Respir Dis 1982;125:400-5.

18 Godfrey S, Mearns M. Pulmonary function and response to exercise in cystic fibrosis. Arch Dis Child 1971;46: 144-51.

19 Quanjer PH, Tammeling GJ, Cotes JE, Pedersen OJ, Peslin $\mathrm{R}$, Yernault J-C. Lung volumes and forced ventilatory flows. Report of European Community for Steel and Coal Working Party standardization of lung function tests. Eur Respir f 1993;6(Suppl 16):5-40.

20 Carter R, Peavler M, Zinkgraf S, Williams J, Fields S Predicting maximal exercise ventilation in patients with Predicting maximal exercise ventilation in patients with
chronic obstructive pulmonary disease. Chest 1987;92: 253-9.

21 Chaitman B. Exercise stress testing. In: Braunwald E, ed. Heart disease: a textbook of cardiovascular medicine. PhilaHeart disease: a textbook of cardiovascilar

22 McLoughlin P, Popham P, Linton RAF, Bruce RCH, Band DM. Use of arterialised-venous blood sampling during 23 Beaver WL, Wasserman K, Whipp BJ. Improved detection of lactate threshold during exercise using a log-log transformation. I Appl Physiol 1985;59:1936-40.

24 Bland JM, Altman DG. Statistical methods for assessing agreement between two methods of clinical measurement. Lancet 1986;i:307-10.

25 Henke KG, Orenstein DM. Oxygen saturation during exercise in cystic fibrosis. Am Rev Respir Dis 1984;129: 708-11.

26 Cropp GJ, Pullano TP, Cerny FJ, Nathanson IT. Exercise tolerance and cardiorespiratory adjustments at peak work capacity in cystic fibrosis. Am Rev Respir Dis 1982;126: $211-6$.

27 Bureau MA, Lupien L, Begin R. Neural drive and ventilatory strategy of breathing in normal children, and in patients
with cystic fibrosis and asthma. Pediatrics 1981;68:187-94.

28 Forster HV, Dunning MB, Lowry TF, Erickson BK, Forster MA, Pan LG, et al. Effect of asthma and ventilatory loading on arterial $\mathrm{PCO}_{2}$ of humans during submaximal loading on arterial $\mathrm{PCO}_{2}$ of humans during

29 Dickstein K, Barvik S, Aarsland RN, Snapinn S, Karlsson J. A comparison of methodologies in detection of the J. A comparison of methodologies in detection of the 30 Smith DA, O'Donnell TV. The time course during 36 weeks' endurance training of changes in $\mathrm{VO}_{2}$ max and anaerobic threshold as determined with a new computerised method. Clin Sci 1984;67:229-36.

31 Caiozzo VJ, Davis JA, Ellis JF, Azus JL, Vandagriff R, Prietto $\mathrm{CA}$, et al. A comparison of gas exchange indices used to detect the anaerobic threshold. I Appl Physiol 1982;35: 1184-9. 